\title{
Usefulness of Rapid Desensitization Therapy for Severe Rash Caused by Molecularly Targeted Drugs Used in the Treatment of Non-small-cell Lung Cancer
}

\author{
Maki Nagase, Nobuharu Ohshima, Masahiro Kawashima, Masahiro Ohgiya, Miki Ikeda, \\ Yoshiteru Morio and Atsuhisa Tamura
}

\begin{abstract}
:
Molecular-targeted drugs (MTDs), such as epidermal growth factor receptor tyrosine kinase inhibitors (EGFR-TKIs) and anaplastic lymphoma kinase inhibitors, are used to treat non-small-cell lung cancer (NSCLC). The incidence of rash caused by EGFR-TKIs and discontinuation of MTDs because of rash are issues. Rapid desensitization therapy (RDT) was performed in five patients who developed severe rash after introduction of MTDs and was successful in four, all of whom showed no rash relapse. RDT may thus be useful for treating rash in patients receiving MTDs for NSCLC.
\end{abstract}

Key words: rapid desensitization therapy, EGFR-TKI, ALK inhibitor, NSCLC

(Intern Med 59: 3201-3205, 2020)

(DOI: 10.2169/internalmedicine.5048-20)

\section{Introduction}

Since 2000, a number of new drugs, such as moleculartargeted drugs (MTDs) and immune checkpoint inhibitors, have been developed and are now being used in the treatment of non-small-cell lung cancer (NSCLC). MTDs that target driver genes required for the development and growth of cancers are currently approved in Japan for epidermal growth factor $(E G F R)$ gene mutations, anaplastic lymphoma kinase $(A L K)$ gene translocations, ROS1 gene translocations, and kinase inhibitors of $B R A F$ gene mutations. The current guidelines in Japan recommend the use of these kinase inhibitors in the first-line treatment of patients positive for these driver gene mutations and translocations. However, many patients experience side effects, and the treatment must be discontinued before it can be effective.

Specific adverse reactions to MTDs include rash, periungual inflammation, and diarrhea. The rate of rash is high. A survey of the specific drug use of erlotinib found that some patients had difficulty continuing treatment because of a rash and that the rate of discontinuation was as high as $8.75 \%$ (1).
The usefulness of rapid desensitization therapy (RDT) has been demonstrated for antituberculosis drugs, anticancer drugs, and MTDs (2-5). We hypothesized that RDT could also be used to resolve rash associated with the use of MTDs. RDT was attempted in five patients who developed a rash during MTD administration in our hospital, and we examined its usefulness.

\section{Case Report}

\section{Patients}

Five patients ( 1 man, 4 women; average age 64 years old, age range 43-75 years old) whose treatment had been discontinued because of the appearance of severe rash after primary treatment with an epidermal growth factor receptor tyrosine kinase inhibitor (EGFR-TKI) or an ALK inhibitor (ALKi) from January 2016 to August 2017 underwent RDT (Table 1). Four patients received an EGFR-TKI, and one received an ALKi. In addition, since the rash had appeared at the initial dose in EGFR-TKI administration, administration was attempted with a decreased dose; however, as the rash became exacerbated after this attempt, the administration 
Table 1. Characteristics of the Five Patients.

\begin{tabular}{|c|c|c|c|c|c|}
\hline & Patient 1 & Patient 2 & Patient 3 & Patient 4 & Patient 5 \\
\hline Age (y) & 75 & 69 & 70 & 63 & 43 \\
\hline Sex & Male & Female & Female & Female & Female \\
\hline Drug used (mg) & Erlotinib 150 & Erlotinib 150 & Erlotinib 150 & Erlotinib 150 & Alectinib 600 \\
\hline $\begin{array}{l}\text { Dose at the time of } \\
\text { discontinuation (mg) }\end{array}$ & Erlotinib 100 & Erlotinib 100 & Erlotinib 100 & Erlotinib 75 & Alectinib 600 \\
\hline Rash severity & $\mathrm{G} 3$ & $\mathrm{G} 3$ & G3 & G3 & Not listed \\
\hline Rash site & $\begin{array}{l}\text { Face, oral mucosa, } \\
\text { neck, and trunk }\end{array}$ & $\begin{array}{l}\text { Face, occiput, } \\
\text { neck, and back }\end{array}$ & $\begin{array}{l}\text { Abdomen, back, and } \\
\text { limbs }\end{array}$ & $\begin{array}{l}\text { Neck, trunk, and } \\
\text { lower extremities }\end{array}$ & $\begin{array}{l}\text { Face, neck, trunk, } \\
\text { and limbs }\end{array}$ \\
\hline Rash type & Punctate & $\begin{array}{l}\text { Acneiform, } \\
\text { paronychia }\end{array}$ & Generalized & Subiculum, redness & Subiculum \\
\hline $\begin{array}{l}\text { Rash status after drug } \\
\text { discontinuation }\end{array}$ & G1 & G1 & $\begin{array}{l}\text { Improvement (no } \\
\text { description of grade) }\end{array}$ & $\begin{array}{l}\text { Improvement (no } \\
\text { description of grade) }\end{array}$ & $\begin{array}{c}\text { Improvement (no } \\
\text { description of grade) }\end{array}$ \\
\hline $\begin{array}{l}\text { Target dose at the time of } \\
\text { RDT (mg) }\end{array}$ & Erlotinib 100 & Erlotinib 100 & Erlotinib 100 & Erlotinib 75 & Alectinib 600 \\
\hline $\begin{array}{l}\text { Max eosinophil count } \\
\text { during appearance of } \\
\text { rash }(\text { per } \mu \mathrm{L})\end{array}$ & 158 & 3,288 & 413 & 308 & 363 \\
\hline $\begin{array}{l}\text { Period from discontinua- } \\
\text { tion to RDT (days) }\end{array}$ & 27 & 40 & 23 & 32 & 17 \\
\hline $\begin{array}{l}\text { Eosinophil count prior to } \\
\text { RDT (per } \mu \mathrm{L})\end{array}$ & 221 & 364 & 119 & 208 & 172 \\
\hline $\begin{array}{l}\text { Eosinophil count after } \\
\text { RDT }(\text { per } \mu \mathrm{L})\end{array}$ & 300 & 637 & 448 & 318 & 353 \\
\hline $\begin{array}{l}\text { Ratio of the eosinophil } \\
\text { count after to before } \\
\text { RDT }\end{array}$ & 1.35 & 1.75 & 3.76 & 1.52 & 2.05 \\
\hline
\end{tabular}

RDT: rapid desensitization therapy, MINO: minocycline hydrochloride, SG: strongest topical steroids, VS: very strong topical steroids, M: moderate topical steroids

was discontinued altogether. All rashes were classified as G3 according to the Common Terminology Criteria for Adverse Events (CTCAE, version 4.0) (6). The median period from the drug administration to the appearance of the rash was 36 days. The rash extended to the face, neck, trunk, and extremities.

All patients provided their written informed consent. This study was reviewed and approved by the ethics committee of the National Hospital Organization, Tokyo National Hospital, and was conducted according to the principles expressed in the Declaration of Helsinki.

\section{RDT}

Fexofenadine $60 \mathrm{mg}$, levocetirizine $5 \mathrm{mg}$, and nizatidine $150 \mathrm{mg}$ were administered on the day before RDT. Fexofenadine $120 \mathrm{mg}$, levocetirizine $5 \mathrm{mg}$, and nizatidine $150 \mathrm{mg}$ were administered 1 hour before RDT. The target drug was then started as a dose of $0.02 \mathrm{mg}$ (target dose $100 \mathrm{mg}$ ) or $0.075 \mathrm{mg}$ (target dose $600 \mathrm{mg}$ ), increased every 15 minutes, and then administered at the daily dose shown in Tables 2 and 3. The target dose in the erlotinib group was reduced to the usual dose (Table 1,2). The reason for reducing the target dose in the erlotinib group was that the rash did not improve even after the dose was reduced in order to attempt continued administration.

\section{Evaluations}

Success with RDT was defined as treatment continuation without exacerbation of the rash. Each patient's rash was graded according to the CTCAE (version 4.0) (6).

\section{Case series}

In Patient 1, the right upper lobe primary lesion decreased in diameter from 40 to $35 \mathrm{~mm}$ after erlotinib administration, and the right cancerous pleural effusion also showed a resolving tendency. However, the right pleural effusion tended to increase after erlotinib discontinuation. In Patient 2, erlotinib was administered, and the primary lesion in the left lower lobe was $32 \mathrm{~mm}$ in diameter and remained unchanged. In Patient 3, erlotinib administration reduced the diameter of the primary lesion in the right middle lobe from 17 to $12 \mathrm{~mm}$. In Patient 4, meningeal dissemination tended to decrease with erlotinib administration. In Patient 5, the primary lesion in the right middle lobe decreased in diameter from 34 to $16 \mathrm{~mm}$ after the administration of alectinib.

All patients were successfully treated with an EGFR-TKI 
Table 2. Erlotinib Rapid-desensitization-therapy Protocol (Target $100 \mathrm{mg} / \mathrm{day}$ ).

\begin{tabular}{ccc}
\hline Day & Time & Erlotinib dose \\
\hline Day 1 & $10: 00$ & $0.02 \mathrm{mg}$ \\
& $10: 15$ & $0.05 \mathrm{mg}$ \\
& $10: 30$ & $0.1 \mathrm{mg}$ \\
& $10: 45$ & $0.2 \mathrm{mg}$ \\
& $11: 00$ & $0.4 \mathrm{mg}$ \\
& $11: 15$ & $0.78 \mathrm{mg}$ \\
& $11: 30$ & $1.56 \mathrm{mg}$ \\
& $11: 45$ & $3.12 \mathrm{mg}$ \\
& $12: 00$ & $6.25 \mathrm{mg}$ \\
& $12: 15$ & $12.5 \mathrm{mg}$ \\
& $12: 30$ & $25 \mathrm{mg}$ \\
Day 2 & $12: 45$ & $50 \mathrm{mg}$ \\
Day 3 & & $50 \mathrm{mg}$ twice a day \\
\hline
\end{tabular}

or ALKi. A moisturizer and topical application of a steroid preparation were used as the treatment for the rashes in all patients. Systemic minocycline was also given to two patients who continued this prescription during their treatment. After RDT, the rash improved to G1 in two of five patients and improved to an unknown grade in three patients (Table 1).

Four of the five patients who underwent RDT were able to continue MTD treatment without developing a rash (Table 1). Three of the four patients who received an EGFRTKI and the one patient who received an ALKi were treated successfully. One of the five patients was unable to continue treatment due to a severe rash (grade 3 ) on day 8 of RDT that made it difficult to continue.

A comparison of eosinophil counts before the start of RDT showed that the 4 patients who were able to continue MTD treatment had a low eosinophil count of $119-221 / \mu \mathrm{L}$, whereas the 1 patient who was unable to continue MTD treatment had a higher count of $364 / \mu \mathrm{L}$. There was no characteristic trend in the change in the eosinophil count from before to after rechallenge in the patients who were or were not able to continue MTD treatment.

Patient 5 was a 43-year-old woman with lung adenocarcinoma, cT4N3M1b stage IV, multiple brain metastases other than the primary lesion, left parietal bone metastases, and multiple metastases in both lungs (Figure). Because the primary lesion was $34 \mathrm{~mm}$ and was positive for $A L K$ gene translocation, treatment with alectinib $600 \mathrm{mg}$ was started. However, a grade 3 rash appeared on day 24 of administration, and alectinib was discontinued on day 26. RDT with alectinib was performed on day 42 after initiation. On day 77 after initiation, the lung metastatic lesion became smaller, and the primary lesion shrank to $26 \mathrm{~mm}$ (Figure). On day 105 after initiation, resolution of brain and bone metastases was observed. We confirmed that alectinib administration could be continued without relapse of the rash after day 105
Table 3. Alectinib Rapid-desensitization-therapy Protocol (Target $600 \mathrm{mg} / \mathrm{day})$.

\begin{tabular}{ccc}
\hline Day & Time & Alectinib dose \\
\hline Day 1 & $10: 00$ & $0.075 \mathrm{mg}$ \\
& $10: 15$ & $0.15 \mathrm{mg}$ \\
& $10: 30$ & $0.3 \mathrm{mg}$ \\
& $10: 45$ & $0.6 \mathrm{mg}$ \\
& $11: 00$ & $1.2 \mathrm{mg}$ \\
& $11: 15$ & $2.4 \mathrm{mg}$ \\
& $11: 30$ & $4.8 \mathrm{mg}$ \\
& $11: 45$ & $9.6 \mathrm{mg}$ \\
& $12: 00$ & $19.2 \mathrm{mg}$ \\
& $12: 15$ & $38.4 \mathrm{mg}$ \\
& $12: 30$ & $76.8 \mathrm{mg}$ \\
& $12: 45$ & $153.6 \mathrm{mg}$ \\
Day 2 & $24: 45$ & $300 \mathrm{mg}$ \\
& & $300 \mathrm{mg}$ twice a day
\end{tabular}

and that the primary lesion had decreased to $7 \mathrm{~mm}$ at day 991 from the start. The rash was not exacerbated by RDT, and this patient was able to continue alectinib treatment over a long period. The treatment was considered to have been successful in this patient.

\section{Discussion}

In many facilities, the usual desensitization therapy in which the treatment is started with a small MTD dose followed by a gradual increase is adopted. However, its disadvantage is that it takes time to increase the drug dose. In the case of lung cancer patients, RDT seemed to be useful, since it can shorten the withdrawal period without any concerns about the pathogenic progression of the cancer and allows for the required dose to be rapidly reached. In addition, it seemed meaningful in preventing anxiety among patients due to drug withdrawal, since whether or not to readminister the drug can be determined after only a few days.

In this study, retreatment with MTDs was possible after RDT in four of the five patients. These findings suggest that RDT may be useful when restarting MTD treatment in patients who had to discontinue treatment because of a rash. RDT required only a few days, and it was possible to restart MTD promptly (an average of 24 days after discontinuation) because the side effects were treated successfully. RDT may facilitate the quick restart of a therapeutic drug by reducing the treatment-free period so that the treatment can be restarted quickly in patients who had to discontinue treatment because of serious side effects.

Erlotinib RDT was successful in three out of four patients, and alectinib RDT was successful in one patient. The target dose in the erlotinib-treated patients with RDT was reduced compared with the initial dose. This was because the rash appeared at the initial administration, and we initially attempted to continue the administration by reducing 


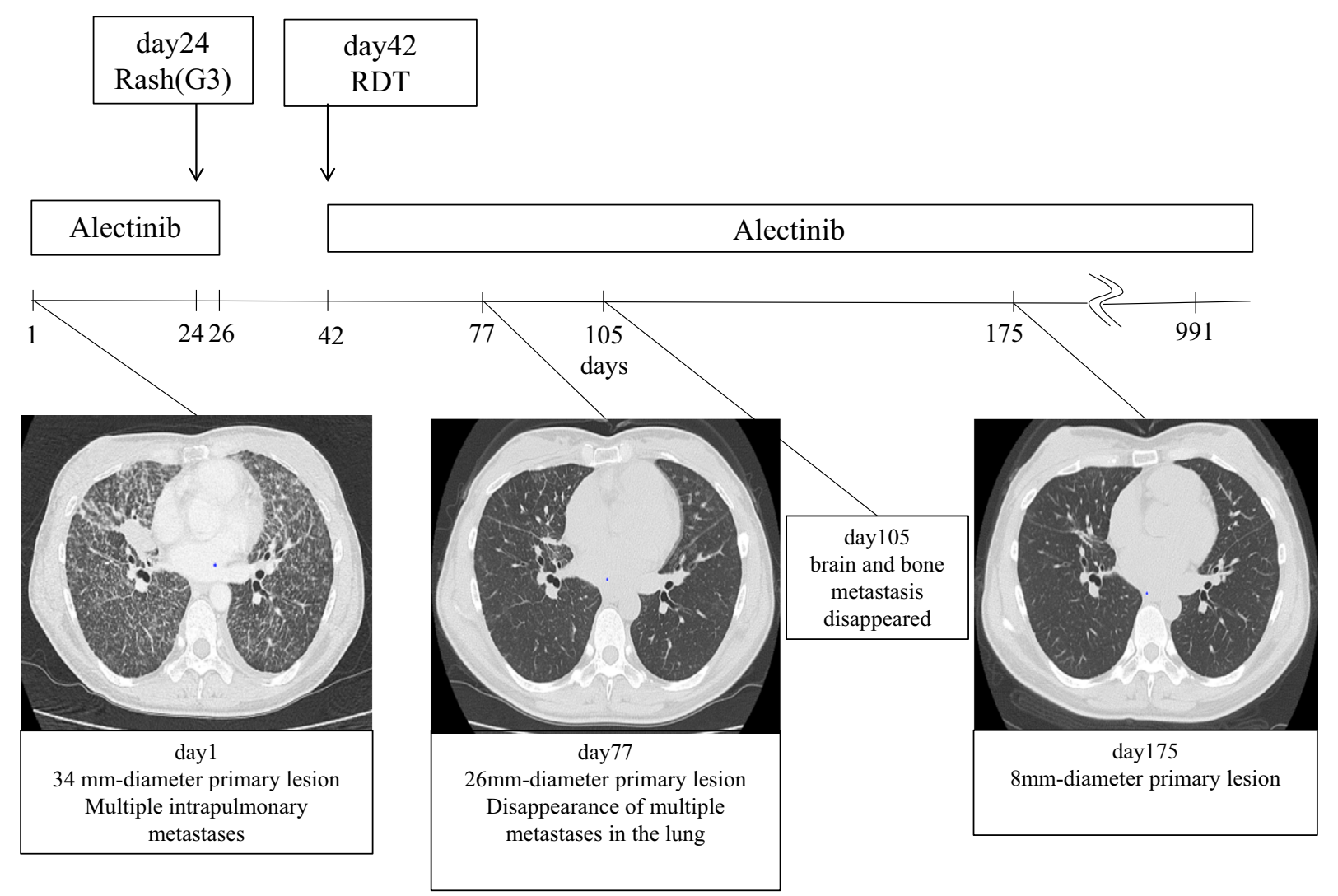

Figure. The clinical course of Patient 5. Day 1: Pretreatment chest computed-tomography image. Multiple intrapulmonary metastases and a 34-mm-diameter primary lesion in the middle lobe can be seen. Day 77: Chest computed tomography image after reintroduction of alectinib after RDT. Shrinkage of the primary lesion and the disappearance of multiple metastases in the lung can be seen. Day 175: The effects of alectinib are maintained.

the dose; however, the rash appeared even with the reduced dosage. In the present cases, RDT was performed by dosing just before the rash appearance. This is the reason why RDT was successful when dose reduction was not. Patients who were unable to restart treatment had a high peripheral-blood eosinophil count of $3,288 / \mu \mathrm{L}$ when the rash appeared during the initial treatment; this was much higher than the range in patients who were able to restart treatment $(158-413 / \mu \mathrm{L})$. The eosinophil count in peripheral blood before RDT was also high when the treatment could not be restarted.

The EGFR is present in the epithelial cells of tumor cells and the normal skin. This receptor binds to ligands, such as EGF, and stimulates the growth, metastasis, and angiogenesis of tumor cells. EGFR-TKIs inhibit EGFR tyrosine kinase activity, thereby inhibiting the EGFR function. In normal skin, the EGFR controls the proliferation and differentiation of keratinocytes. Inhibition of the EGFR by an EGFR-TKI stops keratinocyte proliferation and induces apoptosis, which causes thinning of the entire epidermis and leads to dyskeratosis, thinning of keratinization, and abnormal differentiation of the nail mother cells. All of these processes are thought to contribute to skin disorders, such as the rash associated with EGFR-TKI treatment $(7,8)$. The mechanism responsible for the rash caused by EGFR-TKIs and ALKi seems to differ from an allergic mechanism.
Desensitization therapy aims to induce immune tolerance to allergens by incrementally administering the causative allergen into the body, although the detailed mechanism is unclear. One report indicated that the activity of obesitycoupled fertilizer cells is weakened (9). This suggests that IgE-coupled fertilizer spheres may be involved in some way, but the detailed mechanism is unclear. Other reports have shown the usefulness of RDT for antituberculosis drugs, anticancer drugs, and crizotinib as an MTD (2-5), but these reports did not mention the mechanism of action. Although the mechanism responsible for the skin rash caused by EGFR-TKIs and ALKi seems to differ from that of allergic reactions, as mentioned above, the present results suggest that RDT to prevent skin rash caused by MTDs may be beneficial for drug reintroduction and that allergic factors may also contribute to the skin rash caused by MTDs. One study of RDT suggested that the repeated administration of increasing allergen doses in a short time may lead to exhaustion of storage mediators due to the repeated stimulation and release (10). Exhaustion of storage mediators exacerbates allergic reactions, which may have led to the high success rate in this study.

Our study had a small sample size of only five patients, and our observations will need to be confirmed in a larger study. We were unable to investigate the changes in immu- 
noglobulin levels in this patient group; these changes should also be evaluated in future studies.

Our findings provide novel evidence about the potential usefulness of RDT for preventing rash in patients being treated with erlotinib and alectinib. In addition, this approach may be applicable to other TKIs, such as Osimertinib and Afatinib. RDT may be effective in patients requiring the reintroduction of treatment that had to be discontinued because of the side effect of rash.

The authors state that they have no Conflict of Interest (COI).

\section{References}

1. Nakagawa K, Kudoh S, Ohe Y, et al. Postmarketing surveillance study of erlotinib in Japanese patients with non-small-cell lung cancer (NSCLC): an interim analysis of 3488 patients (POLARSTAR). J Thorac Oncol 7: 1296-1303, 2012.

2. Gomez R, Harter P, Lück HJ, et al. Carboplatin hypersensitivity: does introduction of skin test and desensitization reliably predict and avoid the problem? A prospective single-center study. Int J Gynecol Cancer 19: 1284-1287, 2009.

3. Sasaki Y, Kurashima A, Morimoto K, et al. Experience of rapid drug desensitization therapy in the treatment of mycobacterial dis- ease. Kekkaku 89: 797-802, 2014 (in Japanese).

4. Awad MM, Lax TP, Slawski BR, Shaw AT. Successful desensitization of two patients with ALK-positive lung cancer and hypersensitivity to crizotinib. J Thorac Oncol 9: 1726-1728, 2014.

5. Ban GY, Jeong YJ, Lee SH, et al. Efficacy and tolerability of desensitization in the treatment of delayed drug hypersensitivities to anti-tuberculosis medications. Respir Med 147: 44-50, 2019.

6. U.S. Department of Health and Human Services, Common Terminology Criteria for Advers Events v4.0, U.S. Department of Health and Human Services, Washington, DC, USA, 2010.

7. Lacouture ME. Mechanisms of cutaneous toxicities to EGFR inhibitors. Nat Rev Cancer 6: 803-812, 2006.

8. Kozuki T. Skin problems and EGFR-tyrosine kinase inhibitor. Jpn J Clin Oncol 46: 291-298, 2016.

9. Sancho-Serra Mdel C, Simarro M, Castells M. Rapid IgE desensitization is antigen specific and impairs early and late mast cell responses targeting FceRI internalization. Eur J Immunol 41: 10041013, 2011.

10. Maintz L, Bussmann C, Bieber T, Novak N. Contribution of histamine metabolism to tachyphylaxis during the buildup phase of rush immunotherapy. J Allergy Clin Immunol 123: 701-703, 2009.

The Internal Medicine is an Open Access journal distributed under the Creative Commons Attribution-NonCommercial-NoDerivatives 4.0 International License. To view the details of this license, please visit (https://creativecommons.org/licenses/ by-nc-nd/4.0/).

(C) 2020 The Japanese Society of Internal Medicine

Intern Med 59: 3201-3205, 2020 